\title{
Article
}

\section{Exploring the factors influencing the use of electrically assisted bikes (e-bikes) by stroke survivors: A mixed methods multiple case study}

Boland, Paul, Connell, Louise, Thetford, Clare and Janssen, Jessica Available at http://clok.uclan.ac.uk/34616/

Boland, Paul ORCID: 0000-0003-2267-4295, Connell, Louise ORCID: 00000002-0629-2919, Thetford, Clare ORCID: 0000-0003-2188-3052 and Janssen, Jessica ORCID: 0000-0002-5961-2736 (2020) Exploring the factors influencing the use of electrically assisted bikes (e-bikes) by stroke survivors: A mixed methods multiple case study. Disability and Rehabilitation. ISSN 0963-8288

It is advisable to refer to the publisher's version if you intend to cite from the work. http://dx.doi.org/10.1080/09638288.2020.1817986

For more information about UCLan's research in this area go to http://www.uclan.ac.uk/researchgroups/ and search for <name of research Group>.

For information about Research generally at UCLan please go to http://www.uclan.ac.uk/research/

All outputs in CLoK are protected by Intellectual Property Rights law, including Copyright law. Copyright, IPR and Moral Rights for the works on this site are retained by the individual authors and/or other copyright owners. Terms and conditions for use of this material are defined in the policies page. 
1 Exploring the factors influencing the use of electrically assisted bikes (e-bikes) by

2 stroke survivors: A mixed methods multiple case study

3

4 Abstract

5 Purpose: E-bikes have the potential to overcome some of the barriers that stroke

6 survivors face with regards to physical activity. This study aims to explore the factors

7 that affect e-bike usage by stroke survivors.

8 Methods: A mixed methods multiple case studies design, using semi-structured

9 interviews and GPS data. Subject to GP approval, participants loaned an e-bike or e-trike

10 for up to three months. Interviews were undertaken pre and post intervention. The COM-

11 B behaviour change model acted as a framework for analysis. GPS data relating to

12 journey duration and distance travelled was collected fortnightly.

13 Results: Six participants were recruited; only three loaned an e-bike/e-trike (with

14 adaptations as required). Storage, being unable to get GP approval, and safety were

15 withdrawal reasons. Level of impairment was a factor influencing the type of e-bike used,

16 level of support required and the motivation of the participants.

17 Conclusion: Stroke survivors can use e-bikes although barriers exist. Electrical

18 assistance was a positive factor in enabling some of the participants to cycle outdoors.

19 Due to the small sample size and the number of participants who were able to loan an e-

20 bike, further research is required to determine whether e-bikes are a feasible and effective

21 intervention to increase physical activity for stroke survivors. 
Keywords: Stroke; E-bikes; electrically assisted bikes; factors, physical activity, barriers, active transportation, active travel

\section{Introduction}

The effects of stroke can have a major impact on mobility, affecting many activities of daily living (1), with over half of stroke survivors reporting restrictions to physical and outdoor activities one year after stroke (2). Systematic reviews have identified a mix of physical, environmental, social and motivational barriers to physical activity after stroke $(3,4)$. Barriers include: physical concerns around balance, fear of falling, and the effects of fatigue (4); environmental factors include a lack of transportation and other resources, such as the cost of participation (4); lack of social support from friends and family (3). Physical inactivity can reduce physical fitness, which can contribute to a sedentary lifestyle, thereby increasing the risk of a recurrent stroke and cardiovascular diseases (5). There is currently limited evidence regarding the effectiveness of interventions aimed at increasing physical activity in stroke survivors (6) which has led to calls for new, innovative approaches to the development of interventions $(7,8)$.

Cycling has the potential to be an outdoor form of physical activity for stroke survivors (9). Cycling is a popular method of aerobic exercise for stroke survivors with studies indicating that it can improve walking ability (10) aerobic fitness (11) and muscle strength in sub-acute and post-acute stroke survivors (12). Cycling is also a repetitive low weight-bearing exercise that incorporates the use of the affected side of the body (13, 14) and is seen as a solution for individuals who may have weak lower limbs and struggle with rehabilitation exercises aimed at developing walking ability e.g. treadmill exercise 
(10-12, 15). However, research into cycling within stroke rehabilitation has been

confined to indoor cycling using ergometer devices $(10-12,15)$, and outdoor cycling for

stroke survivors has only recently begun to be explored (9).

Recent exploratory research has shown that stroke survivors value outdoor cycling as it improves their mood, increases independence and to feel part of a community (9). However, road safety, balance, adaptations, social support and not having the energy or strength to pedal are also challenges for stroke survivors (9). Electrically assisted bikes could provide a possible solution to some of these issues. Fitted with a battery and a motor, electrically assisted bikes (commonly referred to as e-bikes), provide electrical assistance when the user is pedalling, allowing the user to cover greater distances with minimal effort (16). There is growing evidence that e-bikes are an alternative form of physical activity for individuals with physical limitations or for those that live sedentary lifestyles (17-19). E-bikes can also have a positive impact on mental health and cognitive function (20) and are an enjoyable form of physical activity that provides autonomy and an opportunity to socialise $(21,22)$. E-bikes can be fitted with adaptations to help overcome the effects of a disability and are available as a tricycle version (e-trike) to overcome issues around balance (23). Recent studies have explored e-bike usage in relation to diabetes (22), and coronary artery disease (24) and are a popular mode of cycling for people with disabilities (25). Although some studies have included stroke survivors as participants $(9,22,26)$, e-bike usage within the context of stroke has yet to be fully explored.

To understand whether e-bikes can be used as a method of physical and outdoor activity for stroke survivors, it is important to first understand the factors that affect their 
use (27). In studies that have investigated factors affecting physical activity in the stroke population there is an increased emphasis on using behaviour change theory as a framework for analysis $(5,28-30)$. This analysis can then form the basis of intervention design (31). The COM-B model is a behaviour change model which has been used within a variety of health contexts, including stroke rehabilitation (28) and most recently within the development of an intervention to reduce sedentary behaviours in stroke survivors (32). Devised by Michie et al (31), the COM-B model is part of a broader framework (the Behaviour Change Wheel) and it proposes that for a behaviour to occur the individual must have both the psychological and physical capability (C), the physical and social opportunity $(\mathrm{O})$, and finally they must be motivated (M; automatic and reflective). Despite criticism that some components of the BCW are not well defined (28), the COM$\mathrm{B}$ model and the BCW have generally been regarded as a useful framework within intervention development $(28,32,33)$.

The aims of this study were: 1) to qualitatively explore the factors that influence the use of e-bikes for stroke survivors, and 2) to quantitatively measure the utilisation of the e-bike by stroke survivors. To the best of the authors' knowledge this will also be the first study to explore both stroke survivors' perceptions of e-bikes and their actual experiences of using e-bikes.

\section{Methods}

\section{Study Design}

The study used a mixed methods multiple case studies design (34) consisting of semi-structured interviews and global positioning system (GPS) data collected from e- 
bikes.

114 STEMH Research Ethics Committee, and all participants provided written informed 115 consent.

\section{Data Collection}

Data were collected over three phases: pre-, during- and post-intervention,

118 which included the loan of an e-bike or e-trike for up to three months. 
120 Semi-structured interviews were carried out pre- and post-intervention. An

121 interview schedule was developed pre-intervention using the COM-B model for guidance

122 (31). For interviews conducted post-intervention a different interview schedule was 123 shaped using both the COM-B model (31) and from responses from fortnightly

124 conversations that took place with the participants during the intervention. These

125 conversations identified if the participants required any additional support, what they

126 were using the bike for, e.g. leisure activities, shopping etc, and to explore if any new

127 factors had emerged. These conversations were recorded on a structured interview sheet,

128 and later used to inform the structure and content of the post-intervention interviews for

129 each participant. All interviews took place in the homes of the participants and were

130 conducted by the same researcher (PB). Interviews were audio recorded and transcribed

131 by PB. Any participants that withdrew from the study prior to the intervention but took

132 part in the pre-intervention interviews gave consent to use their data in the analysis.

133 GPS Data

134 GPS data were collected to assess e-bike use, support the interview data provided during-

135 and post-intervention, and to overcome recall and social desirability bias. Each e-bike/e-

136 trike was fitted with a LK209C GPS tracker made by LK-GPS which recorded movement

137 in two-minute intervals. Data were accessed by one researcher (PB) and downloaded to

138 an Excel spreadsheet every two weeks and the number and duration of journeys made

139 during the intervention were calculated. A journey was deemed as a round-trip (from

140 home-to-home), and only the time spent moving was recorded. Any breaks in the data

141 during a journey, possibly as a result of resting, were not included in the overall journey

142 time. ArcGIS Online (36) was then used to calculate approximate distance covered per 
143 journey. The longitudinal and latitudinal coordinates for each journey were plotted on a

144 map. From there the distance between each location was measured and the approximate

145 distance was calculated, and visualized paths of each journey were captured. During the

146 intervention, two participants (Jim and Rob) experienced technical difficulties with the

147 GPS trackers and the first two weeks of their loan period were not recorded. There also

148 were instances where the trackers failed to record portions of the journey being made

149 meaning these journeys were not included in the final analysis.

150

\section{Intervention}

152

Following the pre-intervention interview and upon receiving GP approval, 154 participants were provided with either an e-bike or e-trike (Figure 1). Over the course of two visits, participants were fitted and trained on the safe use of the e-bike/e-trike. Fitting was carried out by staff from a company that specialised in e-bikes, with two members of

157 the research team present to provide support, should it be required. During the fitting 158 stage, participants were assessed for whether they should use an e-bike or e-trike, and for 159 any alterations that may be required to the brakes and pedals (Figure 2). The selected e160 bike/e-trike was then built to the participant's specification and a second visit was 161 arranged where the participant was trained on its use. Training was carried out by the

162 same individuals from the e-bike company, with at least one member of the research team

163 present. Participants were provided with a helmet and a bike lock, and each bike was 164 fitted with a GPS tracker. Additional visits were arranged on an ad hoc basis. 
Audio recordings from the semi-structured interviews were anonymised,

168 transcribed and imported into NVivo 11 for thematic analysis (37). Coding for the first

169 pre-intervention interview was carried out by two members of the research team (PB and

$170 \mathrm{JJ})$ to ensure consistency. All remaining interviews were coded by one researcher (PB).

171 The COM-B model was used as a framework for the analysis (38).

The GPS data were analysed in Excel and ArcGIS by PB. For each participant,

173 number of journeys, time of journey and approximate distance were analysed

174 descriptively, and Arc-GIS provided a visualised path for each journey.

\section{Results}

176 Case Descriptions

177

Six male participants were recruited, but only three loaned an e-bike/e-trike during

178 the study. All participants were given pseudonyms and a summary of each case study can

179 be found in Table 1. Nine interviews were carried out in total, six pre-intervention, and

180 three post-intervention. Analysis of the interviews identified a number of factors

181 influencing the use of the e-bike by the stroke survivors.

182

183 Cross-case Analysis

184 The following are the results of a cross-case analysis from the GPS data, and the 185 thematic analysis using the COM-B model as a framework. 
The GPS data, post-intervention interviews, and telephone conversations during the intervention, revealed that the participants used the e-bike/e-trike to make a variety of short and long journeys (Table 2). Brian loaned an e-trike for 11 weeks, making seven

190 journeys. Brian cycled predominantly when his son came to visit, when they would both

191 cycle around the estate where he lived for an average time of 16 minutes, and an average

192 distance of approximately $2.45 \mathrm{~km}$. Figure 3 provides a visualised path of the type of 193 journey Brian was making.

Jim loaned an e-bike for eight weeks, the GPS tracker recorded 13 complete journeys. He used the bike for short journeys to make errands to local shops, but also longer journeys of up to 168 minutes covering approximately $45.9 \mathrm{~km}$. Figure 4 is an example of the type of journey Jim was able to make on the e-bike. Jim reported that he cycled as a leisure activity, shopping and for physical fitness. During the postintervention interview Jim reported that he used his car to transport the e-bike to some locations and therefore his averages should be treated with caution.

Rob loaned an e-trike for eight weeks. The GPS trackers recorded three complete journeys in that time. Rob cycled primarily as a means of physical fitness. Journeys were 203 short, with the longest distance being less than $2 \mathrm{~km}$. See Figure 5 for a visualised path 204 of the sort of journey Rob was making. According to the post-intervention interview and 205 from telephone conversations, Rob preferred to cycle on a disused car park away from 206 busy roads. It should also be noted that Rob's wife cycled on the e-trike to and from this 207 location, and therefore this data should be treated with caution. 
210 The following is a summary of the factors identified by all the participants from

211 the interviews carried out pre- and post-intervention, set within the framework of the

212 COM-B model. Quotes are provided, and whether the participant was able to loan an e-

213 bike/e-trike is highlighted in parenthesis.

\section{1.0 Physical Capability}

215 Factors relating to Physical Capability referred to the effects of stroke and how physical

216 impairment impacted the participants ability to use the e-bike/e-trike as well as how it

217 could help overcome fatigue.

218 1.1 Level of impairment

219 Impairment to arms and legs was a factor in the type of e-bike the participants could use,

220 with the most severely impaired participants (Rob and Brian) opting to use the e-trike due

221 to issues around balance. Level of impairment was also a significant factor in the

222 participants ability to cycle. Ismail, who had successfully been fitted for an e-trike had

223 to withdraw from the study at the training stage because he was tensing up on his effected

224 side whilst cycling. This meant he was constantly dragging the e-trike into the curb and

225 because of this he not did feel safe cycling. Similarly, Rob's impairment meant he had

226 to cycle one-handed:

"I feel totally $100 \%$ safe using the bike. It's just me, myself. It's me, really having one hand to steer and one to pull to the right all the time." - Rob (e-trike)

During the loan period, Rob also experienced pain in his calf, as a result of the

231 increased tone in Rob's foot muscles on his affected side which also prevented him from

232 cycling for a period during the intervention. 
$234 \quad 1.2$ Effect on fatigue

235 Before the intervention participants perceived that the e-bike could help

236 overcome post-stroke fatigue, a residual effect of stroke: “...I don't have the same energy levels as normal. The thing about a stroke is you soon get tired... The assistance from the electric will be good." - Brian (etrike)

\subsection{Psychological Capability}

Psychological Capability refers to whether participants had the necessary knowledge or awareness to carry out the behaviour (31). For the participants this was primarily in relation to participants having misconceptions about how the e-bike works.

\subsection{Misconceptions about the e-bike}

In the post-intervention interviews, both Brian and Jim (experienced cyclists before their strokes) described how they thought that the e-bike would operate in a similar way to a mobility scooter and that it would not require constant pedalling to operate. "I thought it would have been motorized but I realized now with having it a while that you've got to put a certain amount of effort in to in to have it moving." - Brian (e-trike)

\subsection{Physical Opportunity}

Physical Opportunity related to factors concerning the e-bike itself, the adaptations required, in addition to environmental factors that effected the participants use of the e-bike. 
3.1 The e-bike/e-trike

Battery life and the additional weight of the e-bike were mentioned as an area for concern by one of the participants who reported that the battery ran out whilst out on a long journey:

“[The battery running out] didn't cause me any problems other than the bike is quite heavy to cycle compared with an ordinary bike without any electrical assist...

\subsection{The electrical assistance}

The electrical assistance provided by the e-bike/e-trike was mostly seen as a

benefit, giving the participants the confidence to cycle further for longer without feeling tired, and manage different gradients, safe in the knowledge that they could get home again.

"I think what the electric cycle does, it gives you the confidence to go further and stay out for longer." - Jim (e-bike)

However, it should also be noted, due to the increased speed of the e-bike/e-trike, participants were only comfortable using a certain level of assistance, and because one of the participants (Rob) was cycling one-handed, he preferred to not use the electrical assistance at all as he deemed it too fast for him. "I just feel that the assistance could be a bit too fast, especially when I hit a hill [or] slope. I just get nervous then." - Rob (e-trike)

\subsection{Adaptations}

Adaptations to the e-trike enabled participants with impairments to their arms and

281 legs to cycle although there were advantages and disadvantages to the adaptations used. 
282 The adaptations to the brakes allowed both brakes to be used simultaneously by the

283 participant's least effected side and were seen as a benefit. However, the adaptations to

284 the pedals required assistance from a member of the family to get on and off the bike

285 which was a challenge for Rob.

286 "I couldn't see that foot because [my wife] was saying "you're on my hands!" but

287 I just couldn't see it to get into the strap." - Rob (e-trike)

Brian, who uses an adapted cycle as part of his leisure and fitness activities at a

local running track, which requires him to be strapped in, was able to adapt himself whilst

using the e-trike without using adapted pedals which he felt was important to him as he did not like being strapped into a bike:

“It's probably a good thing I didn't use an adapter because I've adapted myself to do it, so it's been good... When I arrived at the [running track], [the instructor] straps my foot on, but I don't like that, I don't like being strapped on. At least with this bike on my own I can manage, I can get on and get off, no problem. But you're strapped, you know, you need somebody to undo the strap although I do undo it myself... Subconsciously you think about it, you think if anything would happen." - Brian (e-trike)

\subsection{Environmental factors}

Pre-intervention, all the participants had expectations of using the e-bike to access amenities such parks, shops, and places of physical activity. However, the two participants who were most severely impaired preferred to cycle more locally, either around the estate where he lived progressing slowly, accompanied by a family member (Brian) or cycling around a disused car park away from busy roads (Rob). Additionally, 
307 when Rob visited his local park, he felt that the uneven paths were unsafe to cycle on.

308 Storage of the e-bike was also a determining environmental factor for Ken. Ken felt that

309 his outdoor shed was not a secure place to store an e-trike and due to the size of the e-

310 trike and his small living space it would not have been feasible for Ken to able to store

311 one in his home and therefore withdrew from the study.

\subsection{Social Opportunity}

Social support from family members, and the prospect of using the e-bike to socialise were important factors relating to Social Opportunity. Despite, mostly positive reactions from family members, not everyone was encouraging, and one participant felt there was a stigma attached to using an e-bike.

\subsection{Social Support}

Social support from family members played an integral role in the participants in enabling participants to use an e-bike/e-trike. Pre-intervention, family members provided encouragement to cycle and during the intervention, one participant (Rob) was reliant on his wife to help him mount and dismount the e-trike and cycle to a safe location. "Well yeah, my son was encouraging me to get a bike." - Brian (e-trike) members did not feel he was physically capable. "I've told my sons and my granddaughter, my grandsons. One of them didn't think it won't be a good idea [laughs] to be honest... He said, 'I just don't think you'll be able to manage it." $"$ - Ken (no loan) 

important factor for wanting to use the e-bike by many of the participants. shop and all the rest of it." - Tim (no loan) this was not given to the participant.

\subsection{Stigma}

None of the participants who loaned an e-bike/e-trike cycled as part of a group.

When asked about this, one of the participants felt there was a social stigma attached to using e-bikes by other cyclists:

“Think compared with those people who are avid cyclists on road bikes they're seen as something outside of their circle...I think they probably don't see it as serious cycling...I think there's a lot of ignorance, in fact you do have to pedal it's

Reflective motivation related to motivational factors for wanting to use the e-bike,

349 these focused on belief in capability, a belief that the e-bike was a good form of exercise,

350 it allowed them to return to a previous activity, was a goal to achieve and a way of gaining 351 increasing independence. 
abilities and the control they have over their physical activity, which can be influenced

by people around them, usually family members (29). Within this study there were examples of family members doubting the participants' capabilities, but also there was an example of a participant (Brian) having great belief in his own ability, while family members were concerned about him cycling on his own. As a compromise, Brian cycled primarily when his son came to visit, which eased the fears that his family had and also provided Brian with a companion to cycle with.

5.2 The e-bike is a form of physical activity because I would have gone on my own, but you know people don't seem to think I'm safe [laughs]" - Brian (e-trike) could improve their fitness and mobility. "It's a brilliant idea because you're getting the exercise as well. Which is what you want it for isn't it really?" - Brian (e-trike)

5.3 Increase independence

The participants recognised that using the e-bike was an outdoor activity that would allow them to "get out and about" and gain some independence and possibly relieve the burden placed on friends and family to provide a form of transport. "The freedom. The freedom to go wherever I want to go and do what I want." Ken (no loan) 

"[The e-bike] will actually help me because to ask my friend to come and collect me here it's... I wouldn't say he doesn't mind but it's a bit inconvenient for him. So, if I can make my own way, the better yeah." - Tim (no loan)

\subsection{Return to a previous activity}

Pre-intervention, participants saw using the e-bike as an opportunity to return to a previous activity that they had enjoyed prior to their stroke.

"It wouldn't bother me at all, it would be like being normal. Bikes and cars, I'm just normal." - Brian (e-trike)

\subsection{A goal to achieve}

For the participants, the use of an e-bike was identified as a possible continuation of their rehabilitation and as a goal to achieve:

\subsection{Automatic Motivation}

Factors identified as being linked to Automatic Motivation were regarding emotional reactions to using the e-bike with participants experiencing contrasting feelings at various stages of the study.

\subsection{Cycling as an enjoyable activity}

Prior to the intervention, most of the participants perceived that they would find using the e-bike an enjoyable activity, which was an outcome expressed by those that 
401

402

403

404

405

406

407

408

409

410

411

412

413

414

415

416

417

418

420

421

422

423

424

were able to use the e-bike/e-trike. One participant (Jim) was also encouraged to purchase an e-bike as a result his experience.

“I've just gone out to enjoy riding and I've done that. You know, I've just enjoyed it. We've come back, and we've put it back in the garage and I'm not tired and I'm not out of breath and I don't want to lie down." - Brian (e-trike)

"I think now having used one I think yeah, you know, I like this. And I think I'd use it enough to justify the expense or spend on an e-bike. It's not exactly a fortune, you know but it is something I would enjoy doing.' - Jim (e-bike)

6.2 Fear

Fear of bumping into things and feeling unsafe were experienced by some of the participants. As mentioned above, Ismail withdrew from the study because he did not feel safe using the e-bike due to how his impairment effected his ability to cycle. In addition to feeling nervous using the electrical assistance, Rob also remarked about how he did not feel confident cycling on the street due to a fear of bumping into things:

"I tend to stay off the street because my confidence isn't brilliant on the street. It's down to my own confidence, yeah being out on the street cos I don't want to bump into cars..." - Rob (e-trike)

\section{Summary}

The participants identified several interconnected factors that influenced their use of an e-bike/e-trike as illustrated by Figure 6. Level of impairment, social support, motivation, environmental factors and the e-bike itself were all independent or connected 
425 factors for the participants. For example, level of impairment affected the choice of e-

426 bike, the level of support required, confidence and where participants could travel.

\section{Discussion}

This study explored the factors that influenced the use of e-bikes by stroke

430 survivors. The aims were: 1) to qualitatively explore the factors that influence the use of 431 e-bikes for stroke survivors, and 2) to quantitatively measure the utilisation of the e-bike by stroke survivors. At the time of writing it was the first study to investigate both the perceptions and actual experiences of loaning an e-bike or e-trike by stroke survivors. Of the six participants that took part in the pre-intervention stage, only three went on to loan an e-bike/e-trike. Despite the small sample, the participants identified a variety of factors that both influenced e-bike usage and enabled us to explore the barriers to participation experienced by those who withdrew.

The three participants who loaned an e-bike/e-trike were able to cycle outdoors, 440 although only two participants cycled using the electrical assistance. For these individuals, they reported they felt it gave them the confidence to cycle further for longer which is a significant benefit of using e-bikes $(21,39,40)$. Although, it should be noted that the longest journeys were made by the least impaired participant, who required no

444 adaptations and support. Despite being able to use the e-trike to cycle outdoors, the fact that one participant preferred to cycle without the use of the electrical assistance does raise concerns about whether e-bikes/e-trikes are suitable for everyone. 
previous studies where balance is an issue $(9,23)$. However, the increased size and weight

451 of the e-trike proved a significant barrier for one of the participants, who withdrew from

452 the study because he was unable to store the e-trike in his home. The added weight of the

453 e-bike in general is a commonly cited barrier for e-bike users, along with battery life (21,

$45439,40)$, which was also a concern for one of the participants.

Adaptations aided the two participants with the most severe impairments to use the e-trike. However, the use of pedal adaptations proved to be problematic, requiring assistance by a family member to mount and dismount the e-trike, while another participant spoke of wariness about being strapped in. These findings match those of

460 Greenhalgh et al (9) who also reported that adaptations designed to overcome disability were a cause of anxiety or risk of falls for stroke survivors using adapted cycles. Currently, research into adaptations to e-bikes is limited to one study involving young people with cerebral palsy (41). Stroke survivors experience a diverse range of impairments, requiring an individually tailored approach. This could be an avenue for e-bike manufacturers to explore in future research, not only be in terms of how to adapt an e-bike for the stroke population, but also with regards to the specifics of the e-bike e.g. a lighter frame and longer battery life.

Social support played an important role in enabling the most severely impaired participants to cycle and was a motivating factor. Family members encouraged use of the e-bike, assisted in mounting and dismounting the e-trike, and acted as a companion to cycle with. In addition, during the pre-intervention stage participants also saw the e-bike as an opportunity to socialise and relieve the pressure on relatives to provide a mode of transport. This finding adds to the evidence that social support is important in influencing 
475 physical activity in stroke survivors $(3,4)$ but also that e-bikes can facilitate social

476 interactions and a sense of belonging for those with mobility restrictions $(9,23)$.

477

This study also highlighted the common impression that there is a stigma attached to using e-bikes $(18,21,23,26,39)$. It was perceived by one of the participants that using 480 the e-bike may not be seen as real cycling by other cycle enthusiasts. In this case it did not discourage them from cycling but has been identified as an area for concern in research focusing on older cyclists (23). Similarly, there was also a misconception about how the e-bike works and the need to constantly pedal, making it distinct from mobility aids. Other research has also reported misconceptions around how e-bikes operate which has been attributed to a lack of knowledge $(21,23,26,38)$, which could also explain social stigma. It should also be noted that a reason for one of the participants withdrawing 487 from the study was due to being unable to gain GP approval. Reason for this was not provided, although it may have been due these misconceptions or a lack of knowledge.

Given that the endorsement from healthcare providers is an important factor in increasing physical activity participation in stroke patients (42) future research may investigate the perceptions of healthcare professionals, whether they understand that e-bikes can provide both cognitive and physical benefits (20) and could possibly act as a tool to aid rehabilitation.

Several motivating factors encouraged the use of the e-bike/e-trike. Achieving a goal, returning to a previous activity that was enjoyed prior to stroke and increased independence were all positive factors, which have been attributed to greater engagement in physical activity within the stroke population $(3,9,43)$. However, there were also concerns around fear of bumping into things and a belief among family members that the 
500 participants were not safe cycling despite having confidence in their own ability. These

501 factors have been associated with reduced self-efficacy and an inability to take control of one's behaviour, affecting levels of physical activity post-stroke (44).

503

\section{Strengths and Limitation}

505

506

To the best of the authors' knowledge this was the first study to explore the factors

507 affecting the use of e-bikes by stroke survivors, utilising a method that allowed for the collection of data both on their perceptions and actual experiences. The unique properties of the study and its participants meant we encountered issues around public liability

510 insurance and ethics which necessitated the requirement for GP approval. This in turn had an unexpected impact on participation.

514 who were motivated to use an e-bike, and therefore these findings are not generalisable

515 to the general stroke population. However, due to the exploratory nature of the study, a 516 large sample was unnecessary. Despite the small sample size, the inclusion of six

517 participants from the outset meant that unlike many studies, we were able to explore real 518 barriers.

During the intervention, which took place between May 2018 - Aug 2018, the

UK experienced unusually high temperatures which affected how often the participants wanted to cycle. There were also other periods when they were not cycling, such as during holidays. Other limitations concerned the GPS trackers. Technical issues meant that data

524 for the first two weeks of the intervention was not collected for two of the three 
participants, also data for some trips was not recorded and therefore not included in the

526 analysis. Several e-bike studies have also experienced problems using GPS trackers (45-

527 47) and a possible alternative could be via the use of video observation and biographical

528 interviews as methods of data collection as used by Jones and colleagues for the

529 cycleBoom project which also included a participant who had previously had a stroke

530 (26). Finally, this study did not explore all the different types of e-bikes and adaptations

531 that are available, and some participants may have benefitted from these.

\section{Conclusion}

In conclusion, although a limited sample, this study shows that stroke survivors can use e-bikes and e-trikes, however it highlighted a number of barriers they may encounter with regards to cycling outdoors. The assistance provided by the e-bike was a positive factor in enabling the participants to cycle. However, level of impairment, social support and motivation were all significant factors and e-bikes may not be accessible or suitable for everyone.

\section{Acknowledgments}

542 We would like to thank the participants who participated in this study and Ian Gibbs at I-

543 Cycle Electric (1 North Street, Clitheroe, BB7 1PG) who provided training and technical

544 support throughout this study. This research is part funded by the National Institute for

545 Health Research Applied Research Collaboration North West Coast (NIHR ARC NWC).

546 The views expressed are those of the author(s) and not necessarily those of the National

547 Institute for Health Research or the Department of Health and Social Care. 
550 No potential conflict of interest was reported by the authors.

Word Count: 5948

References

554 1. Kim K, Kim YM, Kim EK. Correlation between the Activities of Daily Living of Stroke Patients in a Community Setting and Their Quality of Life. J Phys Ther Sci. 2014;26(3):417-9.

557 2. de Graaf JA, van Mierlo ML, Post MWM, Achterberg WP, Kappelle LJ, Visser-

558 Meily JMA. Long-term restrictions in participation in stroke survivors under and over 55970 years of age. Disability and Rehabilitation. 2018;40(6):637-45.

$5603 . \quad$ Morris J, Oliver T, Kroll T, Macgillivray S. The importance of psychological 561 and social factors in influencing the uptake and maintenance of physical activity after 562 stroke: a structured review of the empirical literature. Stroke Res Treat.

563 2012;2012:195249-.

564 4. Nicholson S, Sniehotta FF, van Wijck F, Greig CA, Johnston M, McMurdo 565 MET, et al. A Systematic Review of Perceived Barriers and Motivators to Physical 566 Activity after Stroke. 2013;8(5):357-64.

567 5. Outermans J, Pool J, van de Port I, Bakers J, Wittink H. What's keeping people

568 after stroke from walking outdoors to become physically active? A qualitative study, 569 using an integrated biomedical and behavioral theory of functioning and disability. $570 \quad$ BMC Neurol. 2016;16(1):137-.

571 6. Aguiar LT, Martins JC, Nadeau S, Britto RR, Teixeira-Salmela LF, Faria 572 CDCM. Efficacy of interventions to improve physical activity levels in individuals with 573 stroke: a systematic review protocol. 2017;7(1):e012479.

$5747 . \quad$ Morris JH. Body, Person and Environment: Why Promoting Physical Activity

575 (PA) with Stroke Survivors Requires Holistic Thinking. Brain Impairment.

576 2016;17(1):3-15.

5778 8. Pollock A, Baer G, Campbell P, Choo PL, Forster A, Morris J, et al. Physical 578 rehabilitation approaches for the recovery of function and mobility following stroke. 579 Cochrane Database Syst Rev. 2014;2014(4):CD001920-CD.

580 9. Greenhalgh O, McMahon NE, Gaskins N, Khan A, Frings M, Janssen J, et al.

581 An exploration of stroke survivors' perspectives on cycling and the use of electric bikes. 582 Physiotherapy Practice and Research. 2019;40(2):117-26.

583 10. Pang MYC, Charlesworth SA, Lau RWK, Chung RCK. Using Aerobic Exercise 584 to Improve Health Outcomes and Quality of Life in Stroke: Evidence-Based Exercise 585 Prescription Recommendations. Cerebrovascular Diseases. 2013;35(1):7-22.

586 11. Vanroy C, Feys H, Swinnen A, Vanlandewijck Y, Truijen S, Vissers D, et al. 587 Effectiveness of Active Cycling in Subacute Stroke Rehabilitation: A Randomized 588 Controlled Trial. Archives of Physical Medicine and Rehabilitation. 2017;98(8):1576589 85.e5.

590 12. Ferrante S, Pedrocchi A, Ferrigno G, Molteni F. Cycling induced by functional 591 electrical stimulation improves the muscular strength and the motor control of 
individuals with post-acute stroke. Europa Medicophysica-SIMFER 2007 Award Winner. European journal of physical and rehabilitation medicine. 2008;44:159-67. 13. Hancock NJ, Shepstone L, Rowe P, Myint PK, Pomeroy V. Clinical efficacy and prognostic indicators for lower limb pedalling exercise early after stroke: Study protocol for a pilot randomised controlled trial. Trials. 2011;12(1):68. 14. Sibley K, Tang A, Brooks D, Brown D, McIlroy W. Feasibility of Adapted Aerobic Cycle Ergometry Tasks to Encourage Paretic Limb Use After Stroke: A Case Series. Journal of neurologic physical therapy : JNPT. 2008;32:80-7.

600

601 15. Barbosa D, Santos CP, Martins M. The Application of Cycling and Cycling Combined with Feedback in the Rehabilitation of Stroke Patients: A Review. Journal of Stroke and Cerebrovascular Diseases. 2015;24(2):253-73.

604 16. Fishman E, Cherry C. E-bikes in the Mainstream: Reviewing a Decade of Research. Transport Reviews. 2016;36(1):72-91.

\section{Bourne JE, Sauchelli S, Perry R, Page A, Leary S, England C, et al. Health} benefits of electrically-assisted cycling: a systematic review. International Journal of Behavioral Nutrition and Physical Activity. 2018;15(1):116.

18. Dill J, Rose G. Electric bikes and transportation policy. Transportation Research Record. 2012;2314(2314):1-6.

19. Louis J, Brisswalter J, Morio C, Barla C, Temprado J-J. The Electrically Assisted Bicycle: An Alternative Way to Promote Physical Activity. 2012;91(11):93140.

20. Leyland L-A, Spencer B, Beale N, Jones T, Van Reekum CM. The effect of cycling on cognitive function and well-being in older adults. PLOS ONE. 2019;14(2):e0211779.

616 21. Jones T, Harms L, Heinen E. Motives, perceptions and experiences of electric

617 bicycle owners and implications for health, wellbeing and mobility. Journal of

618 Transport Geography. 2016;53:41-9.

619 22. Searle A, Ranger E, Zahra J, Tibbitts B, Page A, Cooper A. Engagement in ecycling and the self-management of type 2 diabetes: a qualitative study in primary care.

622 23. Leger SJ, Dean JL, Edge S, Casello JM. "If I had a regular bicycle, I wouldn't be out riding anymore": Perspectives on the potential of e-bikes to support active living and independent mobility among older adults in Waterloo, Canada. Transportation Research Part A: Policy and Practice. 2019;123:240-54.

\section{Hansen D, Soors A, Deluyker V, Frederix I, Dendale P. Electrical support} during outdoor cycling in patients with coronary artery disease: impact on exercise intensity, volume and perception of effort. Acta cardiologica. 2018;73(4):343-50. 25. Wellbeing Wf. Experiences of disabled cyclists - 2017 survey. 2017. 26. Jones T, Chatterjee, K., Spinney, J., Street, E., Van Reekum, C., Spencer, B., Jones, H., Leyland, L.A., Mann, C., Williams, S. \& Beale, N. cycle BOOM. Design for Lifelong Health and Wellbeing. Summary of Key Findings and Recommendations.

Oxford Brookes University, UK; 2016.

634 27. Morris JH, Oliver T, Kroll T, Joice S, Williams B. From physical and functional 635 to continuity with pre-stroke self and participation in valued activities: A qualitative 636 exploration of stroke survivors', carers' and physiotherapists' perceptions of physical activity after stroke. Disability and Rehabilitation. 2015;37(1):64-77.

28. Connell LA, McMahon NE, Redfern J, Watkins CL, Eng JJ. Development of a

640 Implementation Science. 2015;10(1):34. 
29. Nicholson SL, Donaghy M, Johnston M, Sniehotta FF, van Wijck F, Johnston D, 642 et al. A qualitative theory guided analysis of stroke survivors' perceived barriers and 643 facilitators to physical activity. Disability and Rehabilitation. 2014;36(22):1857-68.

644 30. Walker MF, Hoffmann TC, Brady MC, Dean CM, Eng JJ, Farrin AJ, et al.

645 Improving the development, monitoring and reporting of stroke rehabilitation research:

646 Consensus-based core recommendations from the Stroke Recovery and Rehabilitation

647 Roundtable. 2017;12(5):472-9.

648 31. Michie S, Atkins, L., \& West, R. The Behaviour Change Wheel: A Guide to

649 Designing Interventions. Great Britain: Silverback Publishing; 2014.

650 32. Hall J, Morton S, Hall J, Clarke DJ, Fitzsimons CF, English C, et al. A co-

651 production approach guided by the Behaviour Change Wheel to develop an intervention 652 for reducing sedentary behaviour after stroke. 2020.

653 33. Al-Rawahi S, Newton J, Asimakopoulou K, Masood M, Bulushi N, Yaqoobi K.

654 The Psychological Models of Health-related Behavior in Understanding Sugars Intake

655 in Adults: A Review. Oman medical journal. 2019;35.

656 34. Baxter P, Jack S. Qualitative Case Study Methodology: Study Design and

657 Implementation for Novice Researchers. Qualitative Report. 2010;13.

658 35. Gov.uk. Mobility scooters and powered wheelchairs: the rules N.D [Available

659 from: www.gov.uk/mobility-scooters-and-powered-wheelchairs-rules/eyesight-

660 requirements

661 36. ArcGIS. 2020 [Available from: https://www.arcgis.com/index.html.

662 37. Braun V, Clarke V. Using thematic analysis in psychology. Qualitative Research 663 in Psychology. 2006;3(2):77-101.

664 38. Fyhri A, Heinen E, Fearnley N, Sundfør HB. A push to cycling-exploring the

665 e-bike's role in overcoming barriers to bicycle use with a survey and an intervention

666 study. International Journal of Sustainable Transportation. 2017;11(9):681-95.

667 39. Popovich N, Gordon E, Shao Z, Xing Y, Wang Y, Handy S. Experiences of

668 electric bicycle users in the Sacramento, California area. Travel Behaviour and Society.

$6692014 ; 1(2): 37-44$.

670 40. Van Cauwenberg J, De Bourdeaudhuij I, Clarys P, de Geus B, Deforche BJT. E-

671 bikes among older adults: benefits, disadvantages, usage and crash characteristics.

672 2019;46(6):2151-72.

673 41. Blumenstein T, Zeitlmann H, Alves-Pinto A, Turova V, Lampe R. Optimization

674 of electric bicycle for youths with disabilities. Springerplus. 2014;3:646-.

675 42. Prior PL, Suskin N. Exercise for stroke prevention. Stroke and Vascular

676 Neurology. 2018;3(2):59.

677 43. Resnick B, Michael K, Shaughnessy M, Kopunek S, Nahm ES, Macko RF.

678 Motivators for treadmill exercise after stroke. Top Stroke Rehabil. 2008;15(5):494-502.

679 44. Brouwer-Goossensen D, Genugten Lv, Lingsma H, Dippel D, Koudstaal P,

680 Hertog Hd. Determinants of intention to change health-related behavior and actual

681 change in patients with TIA or minor ischemic stroke. Patient Education and

682 Counseling. 2016;99(4):644-50.

683 45. Cooper AR, Tibbitts B, England C, Procter D, Searle A, Sebire SJ, et al.

684 Potential of electric bicycles to improve the health of people with Type 2 diabetes: a

685 feasibility study. Diabetic Medicine. 2018;35(9):1279-82.

686 46. Hoj TH, Bramwell JJ, Lister C, Grant E, Crookston BT, Hall C, et al. Increasing

687 Active Transportation Through E-Bike Use: Pilot Study Comparing the Health Benefits,

688 Attitudes, and Beliefs Surrounding E-Bikes and Conventional Bikes. JMIR Public

689 Health and Surveillance. 2018;4(4):e10461. 
690 47. Malnes L LS, Bere E, Tjelta LI, Kristoffersen M, Mildestvedt T, et al. How

691 access to an E-bike affects bicycle use and cardiopulmonary fitness in

692 inactive Norwegian adults: A pilot study. [Master's Thesis] In Press 2016. 2016.

693

694

695

696

697 Figure 1: The e-trike used by the participants

698 Figure 2: The adaptations available to the stroke survivors. From left to right -

699 repositioned breaks that could be operated simultaneously by the least effected side, a

700 self-levelling pedal with ankle support, and a pedal with a strap attached

701 Figure 3: A visualised path of the type of journey Brian was making using the e-trike.

702 Figure 4: A visualised path of the type of journey Jim was making using the e-bike.

703 Figure 5: A visualised path of the type of journey Rob was able to make using the e-trike.

704 Figure 6: Interconnecting factors identified by the stroke survivors 
Table 1: Demographic information by case

\begin{tabular}{|c|c|c|c|c|c|c|c|c|c|}
\hline Participants & $\begin{array}{l}\text { Age } \\
\text { (yrs) }\end{array}$ & $\begin{array}{l}\text { First } \\
\text { Strok } \\
\text { e }\end{array}$ & $\begin{array}{l}\text { Time since } \\
\text { stroke } \\
\text { occurred } \\
\text { (months) }\end{array}$ & $\begin{array}{l}\text { Current } \\
\text { methods of } \\
\text { physical } \\
\text { activity }\end{array}$ & $\begin{array}{l}\text { Living } \\
\text { alone or } \\
\text { with a } \\
\text { partner }\end{array}$ & $\begin{array}{l}\text { Able to } \\
\text { loan an } \\
\text { e-bike } \\
(\mathrm{Y} / \mathrm{N})\end{array}$ & $\begin{array}{c}\text { E-bike or } \\
\text { e-trike }\end{array}$ & Adaptations & $\begin{array}{l}\text { Reason for } \\
\text { withdrawal }\end{array}$ \\
\hline Brian & 72 & Yes & 30 & $\begin{array}{l}\text { Walking, going } \\
\text { to the gym and } \\
\text { cycling using an } \\
\text { adapted cycle }\end{array}$ & Partner & $\mathrm{Y}$ & e-trike & Brakes & - \\
\hline Ken & 64 & No & 72 & Fishing & Alone & $\mathrm{N}$ & - & - & $\begin{array}{l}\text { Lack of storage } \\
\text { space }\end{array}$ \\
\hline Jim & 63 & Yes & 1 & $\begin{array}{l}\text { Walking his } \\
\text { dog }\end{array}$ & Partner & Y & e-bike & None & - \\
\hline Rob & 56 & Yes & 40 & $\begin{array}{l}\text { Walking and } \\
\text { attending } \\
\text { exercise classes } \\
\text { twice a week }\end{array}$ & Partner & $\mathrm{Y}$ & e-trike & $\begin{array}{l}\text { Brakes and } \\
\text { pedals }\end{array}$ & - \\
\hline Ismail & 65 & Yes & 36 & Walking & Alone & $\mathrm{N}$ & - & - & $\begin{array}{l}\text { Did not feel safe } \\
\text { using the e-trike }\end{array}$ \\
\hline Tim & 55 & Yes & 5 & Walking & Alone & $\mathrm{N}$ & - & - & $\begin{array}{l}\text { Could not get GP } \\
\text { approval }\end{array}$ \\
\hline
\end{tabular}


710 Table 2: Journey details for the participants who loaned an e-bike/e-trike.

\begin{tabular}{|l|c|c|c|}
\hline Participants & Brian & Jim & Rob \\
\hline Number of weeks loan & 11 & 8 & 8 \\
\hline $\begin{array}{l}\text { Number of completed } \\
\text { journeys recorded }\end{array}$ & 7 & 13 & 3 \\
\hline $\begin{array}{l}\text { Mean average Journey } \\
\text { Length (min) }\end{array}$ & 16 & 48 & 27 \\
\hline Min Journey Length (min) & 10 & 6 & 22 \\
\hline Max Journey Length (min) & 22 & 168 & 32 \\
\hline Average distance (km) & 2.45 & 13.97 & 1.68 \\
\hline Min journey distance (km) & 1.68 & 1.43 & 1.36 \\
\hline Max journey distance (km) & 3.33 & 45.9 & 1.89 \\
\hline
\end{tabular}

